\title{
Molecular dynamics modeling of diffusion bonding
}

\author{
S.D. Chen ${ }^{\mathrm{a}, \mathrm{b}}$, A.K. Soh ${ }^{\mathrm{b}, *}$, F.J. Ke ${ }^{\mathrm{a}, \mathrm{c}}$ \\ ${ }^{a}$ Department of Applied Physics, Beihang University, Beijing 100083, China \\ ${ }^{\mathrm{b}}$ Department of Mechanical Engineering, The University of Hong Kong, Pokfulam Road, Hong Kong \\ ${ }^{\mathrm{c}}$ State Key Laboratory of Non-linear Mechanics (LNM), Institute of Mechanics, Chinese Academy of Sciences, Beijing 100080, China
}

Received 8 November 2004; received in revised form 17 January 2005; accepted 1 February 2005

Available online 25 February 2005

\begin{abstract}
Molecular dynamics simulations on diffusion bonding of $\mathrm{Cu}-\mathrm{Ag}$ showed that the thickness of the interfacial region depended on the stress. The interfacial region became amorphous during diffusion bonding, and it would normally transform from amorphous into crystalline structure when the structure was cooled to the room temperature.
\end{abstract}

(C) 2005 Acta Materialia Inc. Published by Elsevier Ltd. All rights reserved.

Keywords: Molecular dynamics; EAM potential; Diffusion bonding; Interface

\section{Introduction}

Diffusion bonding is a solid-state welding process wherein coalescence of contacting surfaces is produced with minimum macroscopic deformation by diffusioncontrolled processes, which are induced by applying heat and pressure for a finite interval [1]. By means of diffusion bonding, it is possible to bond all materials whose chemical and metallurgical properties are compatible [2]. Since bonding of advanced materials using the classical welding methods [3-5] is not possible due to unexpected phase propagation at the bond interface $[2,6]$, the diffusion bonding technique can be employed to bond such materials. Many theoretical and experimental studies have been done for diffusion bonding [1-8]. However, investigation of diffusion bonding at atomic scale has yet to be carried out. The molecular dynamics (MD) simulation, which is not limited by sample preparation and testing condition and can be used to simulate various mechanical behaviors in nanoscales, is the most widely used numerical method in nanomechan-

\footnotetext{
* Corresponding author. Tel.: +852 285 98061; fax: +852 28585415 .

E-mail address: aksoh@hkucc.hku.hk (A.K. Soh).
}

ics. Weissmann et al. [9] investigated the interface amorphization of $\mathrm{Co}-\mathrm{Zr}$ system using MD; their simulation results showed development of interface amorphization with the increase of temperature. Chen et al. [10] have calculated the interfacial energy of an fcc/bcc interface in $\mathrm{Ni}-\mathrm{Cr}$ alloys. Cherne et al. [11] investigated the amorphization of $\mathrm{Ni} / \mathrm{Zr}$ system. The microstructures of $\mathrm{Cu}-$ Ta interface [12] and $\mathrm{SiO}_{2} / \mathrm{Si}$ interface [13] have also been investigated by means of MD simulations. However, those simulations did not adopt the diffusion bonding technique (i.e., in the condition of high temperature and external pressure). Therefore, the interfacial diffusions were almost invisible and there were no transition regions. Thus, an attempt is made in this manuscript to simulate diffusion bonding of $\mathrm{Cu}-\mathrm{Ag}$ interface using the MD simulation technique.

$\mathrm{The} \mathrm{Cu}-\mathrm{Ag}$ system has been selected because it displays a very rich and intriguing behavior $[14,15]$. In terms of the well-known Hume-Rothery rules [16], the eutectic $\mathrm{Cu}-\mathrm{Ag}$ system is peculiar as the two noble fcc metals, with atomic size difference still within the $15 \%$ limit, are almost completely immiscible below $\sim 650 \mathrm{~K}$ [17]. A lot of researchers have produced $\mathrm{Cu}-\mathrm{Ag}$ alloys using various processing methods $[14,15,18-20]$, the vast 
majority of the alloys produced were fcc crystalline solid solutions. The formation of amorphous $\mathrm{Cu}-\mathrm{Ag}$ solid solutions is achievable only partially and under certain specific conditions [20]. The objective of the present study is to investigate what kind of solution will form during diffusion bonding of $\mathrm{Cu}-\mathrm{Ag}$ interface using the MD approach.

\section{Simulation procedure}

In MD simulations, inter-atomic potentials play a very important role. Considerable progress has been made in recent years in the development of empirical and semi-empirical many-body potentials. The well established embedded atomic method (EAM) [21,22] has been successfully used in modeling elastic properties, defect formation energy and fracture mechanisms of various close-packed bulk metals. The modified EAM model proposed by Johnson $[23,24]$ was adopted in our simulation.

In the present MD simulations, the system consists of mono-crystal copper and mono-crystal silver slab. The top surface of copper and silver are both on $(100)$ planes. The number of atoms in the system was chosen such that the misfit at the $\mathrm{Cu}-\mathrm{Ag}$ interface was as close as possible to the experimental ratio of the lattice constants, and the structure size was manageable. The number of atoms in one copper layer was chosen as $28 \times 28 \times 2=1568$ and in silver as $25 \times 25 \times 2=1250$, since $28 / 25=1.12$ is very close to the ratio of the lattice constants of $\mathrm{Ag}$ and $\mathrm{Cu}$, which is 1.13 (the lattice constant of silver and copper are $4.089 \mathrm{~A}$ and $3.615 \mathrm{~A}$, respectively.). The layers of $\mathrm{Cu}$ and $\mathrm{Ag}$ were chosen as 32 and 28, therefore, the total number of $\mathrm{Cu}$ and $\mathrm{Ag}$ atoms were 50176 and 35000 , respectively. Periodic boundary conditions were implemented in the two transverse (i.e., $x$ and $y$ ) directions. Two layers of atoms at the bottom of the $\mathrm{Cu}$ slab and at the top of Ag slab were fixed.

The initial velocities of atoms were assumed based on the Maxwellian distribution. The Newton's equations of motion for the atoms in the structure were numerically integrated using the Leap-Frog algorithm [25] with a fixed time step of $2 \mathrm{fs}$. The external pressure in the transverse directions was maintained at atmospheric pressure using Berendsen barostat [26], and three different stresses were applied in the $Z$ direction, i.e., $50 \mathrm{MPa}$, $100 \mathrm{MPa}$ and $150 \mathrm{MPa}$. The simulations were performed under constant temperature, which was kept at a desired value by scaling the atomic momentum. No significant discrepancies were found by using three different thermostats, i.e., Berendsen [26], Andersen [27] and NoseHoover [28] thermostat to control the temperature. A calculation has also been performed where in which only atoms far from the interface were temperature controlled under $150 \mathrm{MPa}$. The result obtained is almost the same compared with the case where a thermostat was used on all the dynamics. Thus, the temperature was controlled by scaling the velocities of all atoms for every time step.

In order to ensure sufficient interfacial diffusion, all the MD runs were firstly performed on the initial configuration of the structure at the temperature of $1150 \mathrm{~K}$ (the experimental melting point of $\mathrm{Cu}$ and $\mathrm{Ag}$ are $1356 \mathrm{~K}$ and $1234 \mathrm{~K}$, respectively) for $200 \mathrm{ps}$. Subsequently, the structure was cooled down from $1150 \mathrm{~K}$ to $300 \mathrm{~K}$ at four different cooling rates, i.e., $5 \times 10^{11}$ $\mathrm{K} / \mathrm{s}, 2 \times 10^{12} \mathrm{~K} / \mathrm{s}, 5 \times 10^{12} \mathrm{~K} / \mathrm{s}$ and $5 \times 10^{13} \mathrm{~K} / \mathrm{s}$.

\section{Results and discussions}

\subsection{Diffusion between interfaces}

Fig. 1 shows the cross-section of the structure obtained under different stress after 200 ps. When the stress was $50 \mathrm{MPa}$, there was no observable diffusion between the $\mathrm{Cu}$ and $\mathrm{Ag}$, which were still fcc structures (refer to Fig. 1(a)). It is clearly shown in Fig. 1(b) that there were few $\mathrm{Cu}$ atoms diffused into $\mathrm{Ag}$ when the stress was $100 \mathrm{MPa}$. The situation was changed significantly when the stress was $150 \mathrm{MPa}$, at which there was obvious

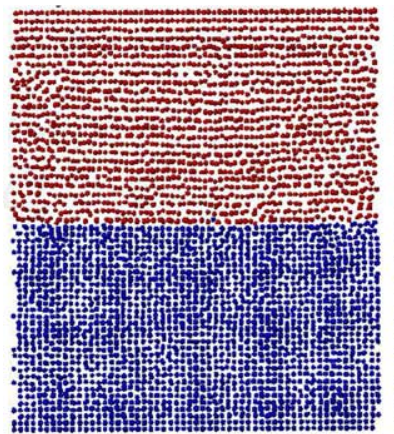

(a)

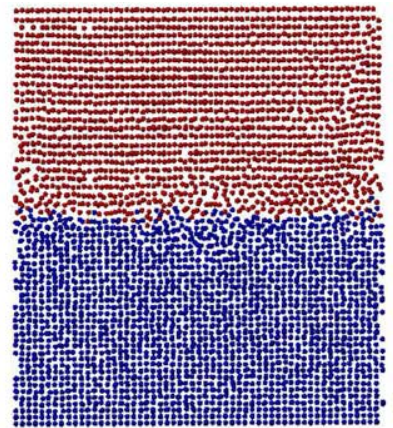

(b)

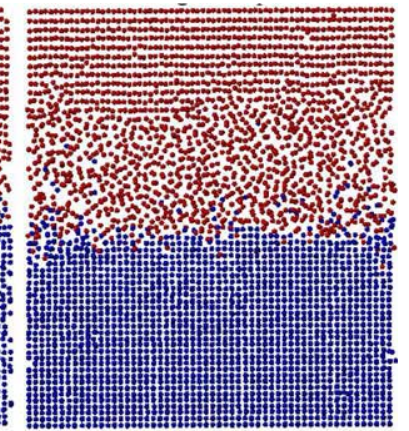

(c)

Fig. 1. Snapshots of cross-section obtained at different stress after 200 fs. The blue are copper atoms and the red are silver atoms. (a) $50 \mathrm{MPa}$, (b) $100 \mathrm{MPa}$, (c) $150 \mathrm{Mpa}$. (For interpretation of the references in color in this figure legend, the reader is referred to the web version of this article.) 
interfacial diffusion between $\mathrm{Cu}$ and $\mathrm{Ag}$, and a lot of $\mathrm{Cu}$ atoms diffused into the Ag slab to form a rich-Ag interface. Fig. 1(c) also clearly shows that the interface and part of the Ag near the interface became amorphous. These simulation results are in agreement with those of Weissmann et al. [9], who investigated the interface of a $\mathrm{Co}-\mathrm{Zr}$ system and their simulations show that the interface became disordered at high temperature.

Fig. 2 shows the concentration distributions of $\mathrm{Cu}$ and $\mathrm{Ag}$ atoms along the $Z$ direction obtained under different stress after 150 ps. With reference to Fig. 2(c), a region is defined as interfacial region if the concentration of $\mathrm{Cu}$ and $\mathrm{Ag}$ atoms are both over 5 at.\%. Thus, the thickness of the interfacial region can be estimated from the concentration curves. From Fig. 2(a), the thickness of the interfacial region was determined to be only approximately $5 \mathrm{~A}$ when the stress was $50 \mathrm{MPa}$, this indicates that there was no obvious diffusion between $\mathrm{Cu}$ and $\mathrm{Ag}$ atoms. From Fig. 2(b) it can be seen that the thickness of the interfacial region, which is approximately $9 \mathrm{~A}$, was larger than that in Fig. 2(a), but it was still very thin. With reference to Fig. 2(c), when the stress was $150 \mathrm{MPa}$, the thickness of the interfacial region was raised to approximately $27 \mathrm{~A}$. In addition, Fig. 2(c) also shows that the interfacial region consisted of rich- $\mathrm{Cu}$ and rich-Ag phase, and the thickness of rich-Ag phase was larger than that of the rich$\mathrm{Cu}$ phase. This indicates that the main diffusion was from $\mathrm{Cu}$ to Ag slab. Fig. 3 shows the thickness of the interfacial regions versus time under $150 \mathrm{MPa}$. From Fig. 3 it can be seen that the thickness is increased in stepwise manner. After about $120 \mathrm{ps,} \mathrm{the} \mathrm{thickness} \mathrm{did}$ not increase again, which but showed fluctuation. This indicates that the interfacial region would reach a maximum thickness not withstanding the fact that the diffusion and thickness depend on the stress, i.e., the higher the stress the thicker the interface was.

\subsection{The effect of cooling rate}

Since the diffusions under a relatively small stress of $50 \mathrm{MPa}$ and $100 \mathrm{MPa}$ were not obvious, henceforth,

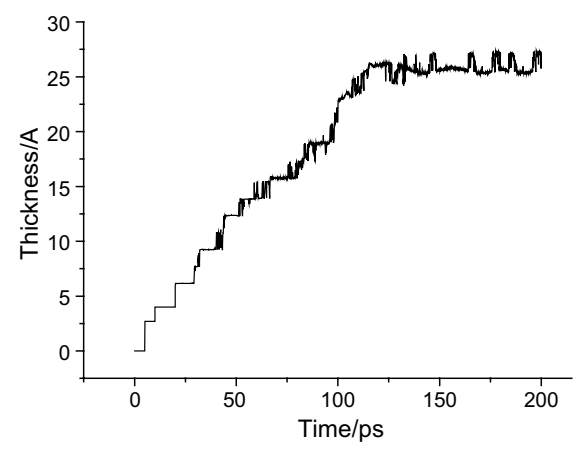

Fig. 3. Thickness versus time under $150 \mathrm{MPa}$.

we only consider the cooling process under $150 \mathrm{MPa}$. The structure was cooled from $1150 \mathrm{~K}$ to $300 \mathrm{~K}$ at four different cooling rates, i.e., $5 \times 10^{11}, 2 \times 10^{12}, 5 \times 10^{12}$ and $5 \times 10^{13} \mathrm{~K} / \mathrm{s}$.

Fig. 4 shows the average internal energy versus temperature when the structure was cooled down at different cooling rates. Since we have already learned that the interface became amorphous during diffusion under $150 \mathrm{MPa}$ stress, the downward shift of the energy level during cooling is believed to be due to the structural transition of the interface. However, this cooling process is different from crystallization of liquid metal because

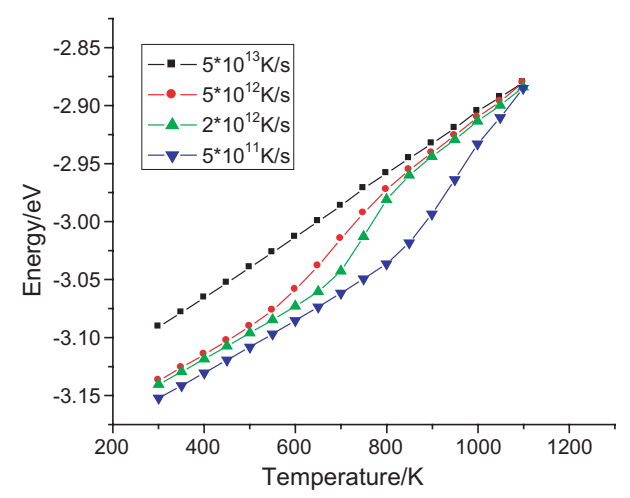

Fig. 4. Internal energy versus temperature during cooling at different cooling rates. (a)

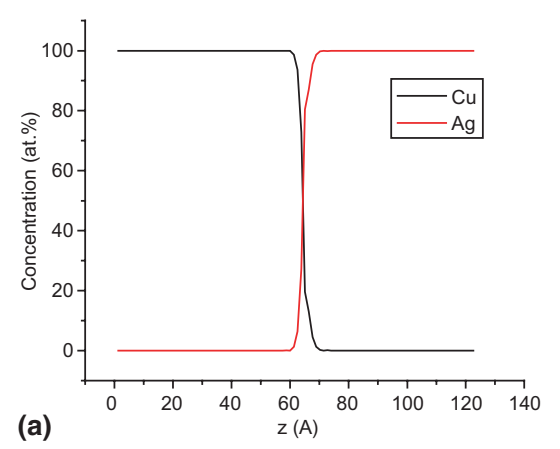

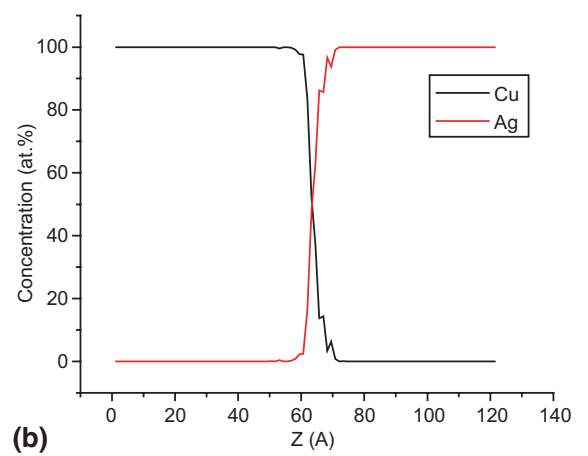

Fig. 2. Concentration distribution along $Z$ direction obtained under different stress after 150 ps. (a) $50 \mathrm{MPa}$, (b) $100 \mathrm{MPa}$, (c) $150 \mathrm{MPa}$. 
the former did not have certain transition temperature. In fact, the transition of the structure was observed over a temperature range. Different cooling rates led to different temperature ranges, and the larger the cooling rate the lower the transition temperature range. At $5 \times$ $10^{11} \mathrm{~K} / \mathrm{s}$ cooling rate, the structure began to change at about $1000 \mathrm{~K}$; whereas, at $2 \times 10^{12} \mathrm{~K} / \mathrm{s}$ and $5 \times 10^{12} \mathrm{~K} / \mathrm{s}$ cooling rate, the structure began to change at about $800 \mathrm{~K}$. However, at $5 \times 10^{13} \mathrm{~K} / \mathrm{s}$ cooling rate, the variation of energy was continuously linear. This indicates that the structure of the interface did not change during cooling. In fact, the amorphous interface was formed before cooling.

The radial distribution function (RDF) $\mathrm{g}(\mathrm{r})$ describes the fluctuations in density around a given atom [29], which can be thought as the average number of atoms found at a given distance in all directions. It is one of the most important structural quantities characterizing a molecular system. There was no concentration redistribution on cooling. From Fig. 3, it can be seen that at high temperature the interfacial region would reach a maximum thickness once the diffusion process has reached a stage that no further significant diffusion can be observed. The diffusion of atoms becomes more difficult when the temperature is decreased. Thus, the concentration should not redistribute on cooling even if the cooling rate is very slow. Then the interfacial region was kept the same to analyse the structure during cooling. Fig. 4 shows the RDF of the interfacial region dur- ing the cooling process at different cooling rates. The RDF shows that the structure was amorphous as it was cooled from $1150 \mathrm{~K}$ to $1000 \mathrm{~K}$ in Fig. 5(a); at $900 \mathrm{~K}$ the RDF began to exhibit the fcc crystalline structure. However, the RDF began to exhibit the fcc crystalline structure at $700 \mathrm{~K}$ (refer to Fig. 5(b)) and $500 \mathrm{~K}$ (refer to Fig. 5(c)) when the cooling rates were $2 \times 10^{12} \mathrm{~K} / \mathrm{s}$ and $5 \times 10^{12} \mathrm{~K} / \mathrm{s}$, respectively. From these three RDFs, we may conclude that the amorphous interface would be transformed into one with fcc structure when the cooling rate was not higher than $5 \times 10^{12} \mathrm{~K} / \mathrm{s}$. For the rate of $5 \times 10^{13} \mathrm{~K} / \mathrm{s}$, the RDF exhibits the amorphous structure even at the room temperature (refer to Fig. 5(d)), which indicates that an amorphous interfacial region was formed. Qi et al. [30] have studied the glass formation of $\mathrm{Cu}_{40} \mathrm{Ag}_{60}$ alloy. They observed that the retention of amorphous structure required extremely high cooling rates $\left(1 \times 10^{14} \mathrm{~K} / \mathrm{s}\right)$, which is consistent with our simulation result.

The pair analysis (PA) technique proposed by Honeycutt and Andersen [31] has been widely used in recent years to examine local structural features. This approach can provide very vivid information about local symmetry of the atomic arrangement, which cannot be obtained by the conventional radial distribution function. The PA method employs four parameters, i.e., $i$, $j, m$ and $n$, to distinguish the bond pairs; $i=1$ indicates the formation of a bond pair between any two atoms, whereas, $i=2$ indicates that the two atoms do not form
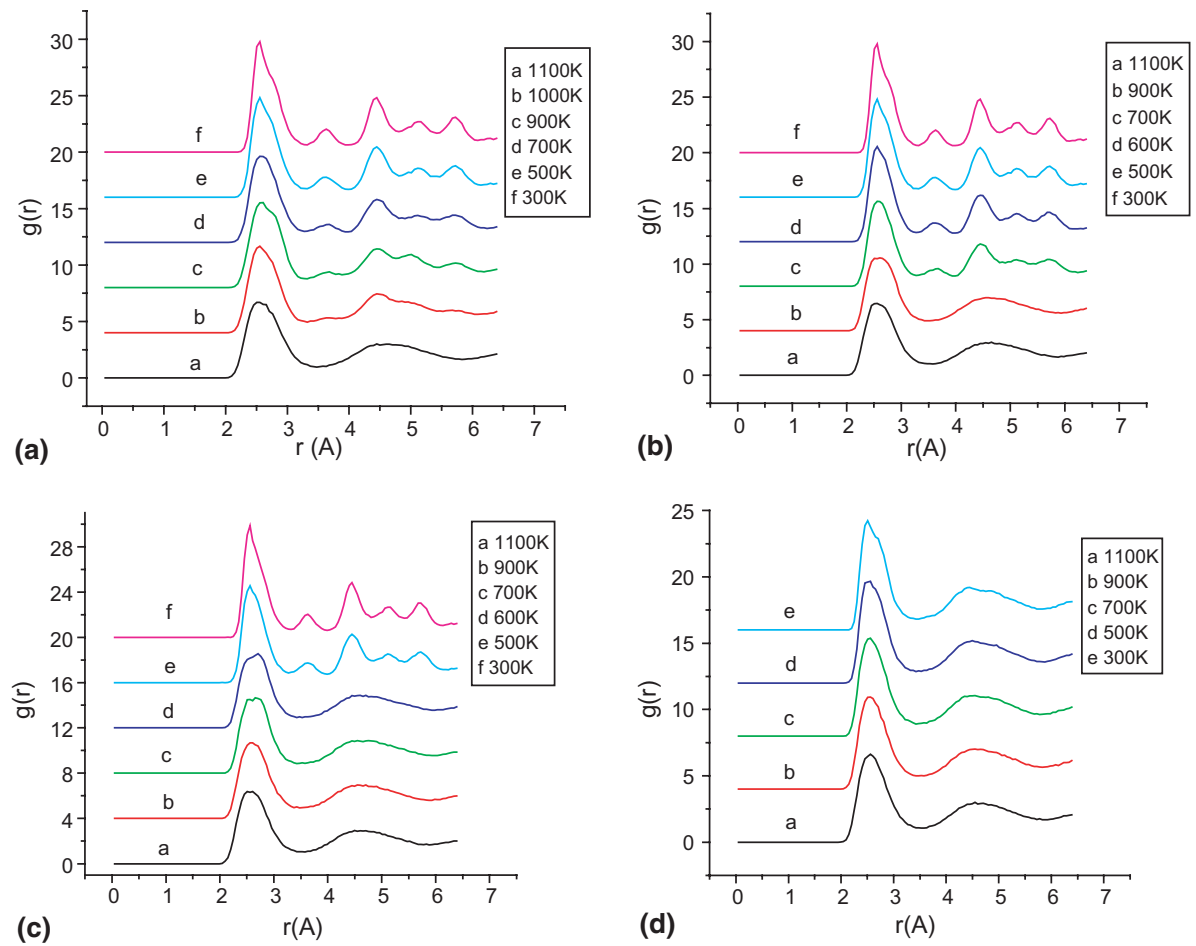

Fig. 5. Radial distribution function (RDF) of interface during the cooling processes at different cooling rates. (a) $5 \times 10^{11} \mathrm{~K} / \mathrm{s}$, (b) $2 \times 10^{12} \mathrm{~K} / \mathrm{s}$, (c) $5 \times 10^{12} \mathrm{~K} / \mathrm{s}$, (d) $5 \times 10^{13} \mathrm{~K} / \mathrm{s}$. 

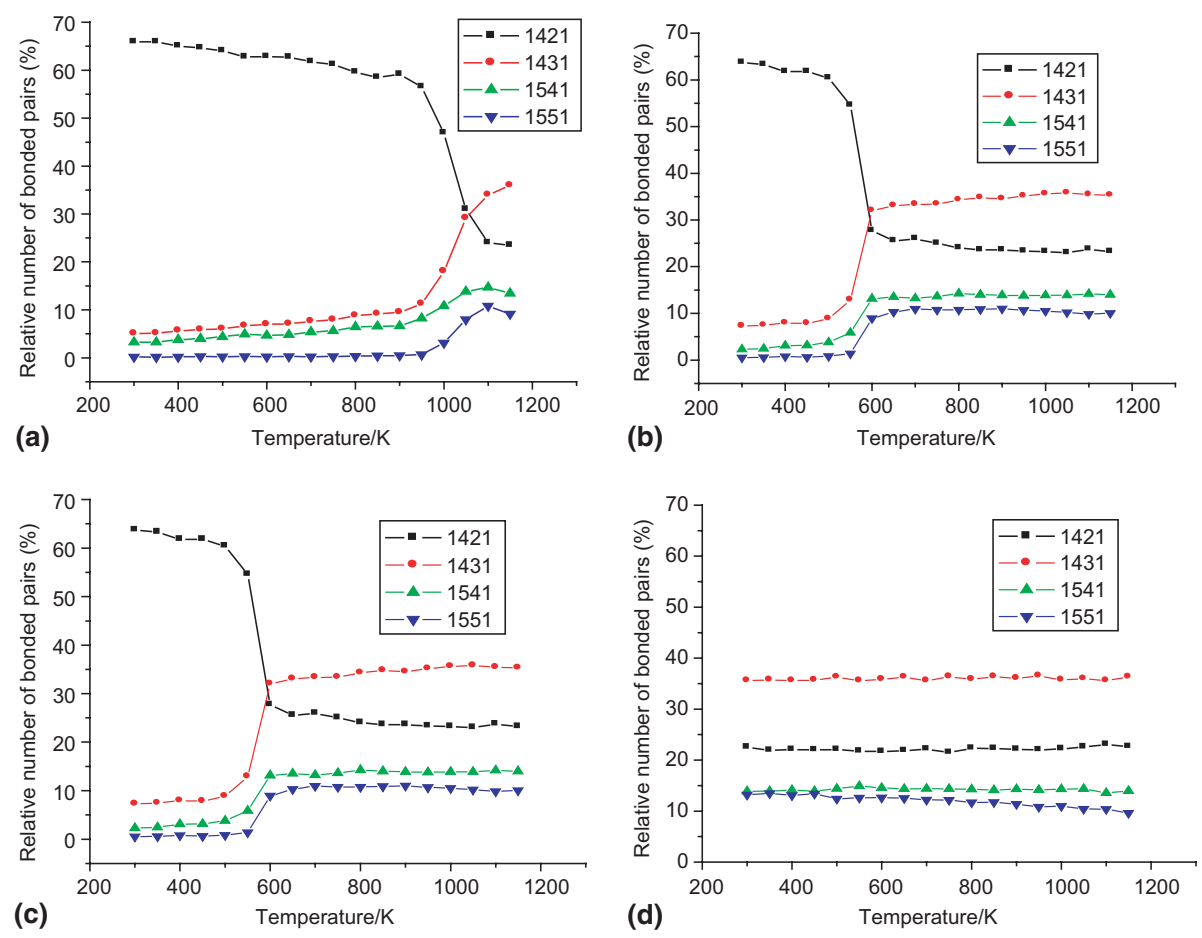

Fig. 6. Relative numbers of various bonded pairs in the interfacial region versus temperature at different cooling rates. (a) $5 \times 10^{11} \mathrm{~K} / \mathrm{s}$, (b) $2 \times 10^{12} \mathrm{~K} / \mathrm{s}$, (c) $5 \times 10^{12} \mathrm{~K} / \mathrm{s}$, (d) $5 \times 10^{13} \mathrm{~K} / \mathrm{s}$.

a bond; the parameter $j$ denotes the number of nearneighbor atoms; the parameter $m$ represents the number of bonds formed among near neighbors; and the parameter $n$ indicates the way in which bonds are formed among near neighbors. The PA can be used to distinguish various local packing orders, in particular fcc, bcc, hcp, and liquid environment. For example, most of the bonded pairs in fcc are of type 1421, bcc are of type 1442 and 1661, liquid and amorphous are of type 1551,1431 , and 1541. There were four major pairs in the interfacial region before cooling. The total relative numbers of type 1431, 1541 and 1551, which are related to amorphous structure, was about $60 \%$. This indicates that the amorphous structure was predominant in the interfacial region. Thus, the four major pair types (i.e., 1421, 1431, 1541 and 1551) were monitored during quenching.

Fig. 6(a)-(d) show the relative fraction of the various PA pair types versus temperature for quenching rates of $5 \times 10^{11}, 2 \times 10^{12}, 5 \times 10^{12}$ and $5 \times 10^{13} \mathrm{~K} / \mathrm{s}$, respectively. Fig. 6(a) clearly indicates that an abrupt decrease of the relative number of 1431,1541 and 1551 pairs occurred at about $1000 \mathrm{~K}$ when the cooling rate was $5 \times 10^{11}$ $\mathrm{K} / \mathrm{s}$, and the population of 1421 pairs, which are related to fcc structure, showed an abrupt increase at the same temperature, which indicates the transition from amorphous to fcc crystalline structure. The two case shown in Fig. 6(b) and 6(c) are similar to that in Fig. 6(a), i.e., the relative number of 1421 pairs showed an abrupt increase at about $700 \mathrm{~K}$ and $550 \mathrm{~K}$ when the cooling rate were $2 \times 10^{12}$ and $5 \times 10^{12} \mathrm{~K} / \mathrm{s}$, respectively. Fig. $6(\mathrm{~d})$ shows an entirely different case, in which the relative number of 1421, 1431 and 1541 pairs more or less maintained the same fractions, and there was a little increase in the number of 1551 pairs. This indicates that an amorphous interface was formed at this cooling rate. In fact, almost all the $\mathrm{Cu}-\mathrm{Ag}$ alloys produced in experiments $[14,15,18-20]$ were fcc crystalline solid solutions, and the formation of amorphous $\mathrm{Cu}-\mathrm{Ag}$ solid solutions was only partially achievable under certain specific conditions [20]. This experimental finding is consistent with our simulation result.

\section{Conclusions}

In this paper, the EAM potential was adopted to investigate the process of diffusion bonding between $\mathrm{Cu}$ and $\mathrm{Ag}$. A series of simulations have been performed and the conclusions drawn are as follows:

(1) Stress played a very important role in diffusion bonding. When the stress was lower than $100 \mathrm{MPa}$, there was hardly any diffusion observed at the interface.

(2) The thickness of the interfacial region depended on the stress. The higher the stress, the thicker the interfacial region was. 
(3) The interfacial region became amorphous under high temperature and high stress during diffusion bonding.

(4) Normally, the interfacial region would transform from amorphous into crystalline when the structure was cooled to room temperature. The transition temperature depended on the cooling rate, the larger the cooling rate the lower the transition temperature was. An amorphous interface would only form under very high cooling rate.

\section{Acknowledgments}

Support from the Research Grants Council of the Hong Kong Special Administrative Region, China (Project Nos. HKU 7195/04E and 7203/03E) and the National Natural Science Foundation of China (Grant No. 10372012, 10472118, 10432050) are acknowledged.

\section{References}

[1] Owczarski WA, Paulonis DF. Weld J 1981;62:22.

[2] Guo ZX, Ridley N. Mater Sci Technol 1987;3(11):945.

[3] Fukumoto S, Hirose A, Kobayashi D. Prod Eng 1989;46.

[4] Aleman B, Gutierrez I. Mater Trans A 1995:437.

[5] Aleman B, Guterrez I, Urcola JJ. Scripta Mater 1997;36(5):509.

[6] Askeland DR. The science and engineer of materials. Hong Kong: Van Nostrand Reinhold; 1989.
[7] Yilmaz O, Celik H. J Mater Process Technol 2003;141:67.

[8] Wang O, Ohashi O, Yamaguchi N, et al. J Electron Microsc 2004;53(2): 157 .

[9] Weissmann M, Ramfrez R, Kiwi M. Phys Rev B 1992;46: 2577.

[10] Chen JK, Frakas D, Reynolds WT. Acta Mater 1997;45: 4415.

[11] Cherne FJ, Baskes MS, Schwarz RB. J Non-Cryst Solids 2003;317:45

[12] Heino P. Comput Mater Sci 2001;20:157.

[13] Watanabe T, Tatsummura K, Ohdomari I. Applied surface science, in press.

[14] Klassen T, Herr U, Averback RS. Acta Mater 1997;45:2921.

[15] Wei LC, Averback RS. J Appl Phys 1997;81:613.

[16] Hume-Rothery W. Atomic theory for students of metallurgy. London: The Institute of Metals; 1969.

[17] Massalski TB, editor. Binary alloy diagrams, vol. 1. Metals Park: ASM; 1986. p. 29.

[18] Cantor B, Cahn RW. Acta Metall 1976;24:845.

[19] Wu F, Bellon P, Melmed AJ, et al. Acta Mater 2001;49:453.

[20] Sheng HW, Wilde G, Ma E. Acta Mater 2002;50:475.

[21] Hockney RW. Methods Comput Phys 1970;9:136.

[22] Daw MS, Baskes MI. Phys Rev Lett 1983;50(17):1285.

[23] Foiles SM, Baskes MI, Daw MS. Phys Rev B 1986;33(12): 7983.

[24] Johnson RA. Phys Rev B 1989;39:12554.

[25] Zhou XW, Wadley HNG, Johnson RA, et al. Acta Mater 2001;49:4005.

[26] Berendsen HJC, Postma JPM, Gunsteren WFV, et al. J Chem Phys 1984;81:5.

[27] Andersen HC. J Chem Phys 1980;72:2384.

[28] Hoover WG. Phys Rev A 1985;31:1695.

[29] Heermann DW. Computer simulation methods in theoretical physics. Berlin: Springer; 1990.

[30] Qi L, Zhang HF, Hu ZQ. Intermetallics 2004;12:1191.

[31] Honeycutt JD, Andersen HC. J Phys Chem 1987;91:4950. 